\title{
Front-Running and Market Quality: An Evolutionary Perspective on High Frequency Trading
}

DOI:

10.1111/irfi.12159

\section{Document Version}

Accepted author manuscript

Link to publication record in Manchester Research Explorer

\section{Citation for published version (APA):}

Schenk-Hoppê, K. R., Lensberg, T., \& Hens, T. (2017). Front-Running and Market Quality: An Evolutionary Perspective on High Frequency Trading. International Review of Finance. https://doi.org/10.1111/irfi.12159

\section{Published in:}

International Review of Finance

\section{Citing this paper}

Please note that where the full-text provided on Manchester Research Explorer is the Author Accepted Manuscript or Proof version this may differ from the final Published version. If citing, it is advised that you check and use the publisher's definitive version.

\section{General rights}

Copyright and moral rights for the publications made accessible in the Research Explorer are retained by the authors and/or other copyright owners and it is a condition of accessing publications that users recognise and abide by the legal requirements associated with these rights.

\section{Takedown policy}

If you believe that this document breaches copyright please refer to the University of Manchester's Takedown Procedures [http://man.ac.uk/04Y6Bo] or contact uml.scholarlycommunications@manchester.ac.uk providing relevant details, so we can investigate your claim.

\section{OPEN ACCESS}




\title{
Front-running and market quality: An evolutionary perspective on high frequency trading
}

Current version: August 31, 2017; first version: March 7, 2017.

\begin{abstract}
We study front-running by high frequency traders (HFTs) in a limit order model with continuous trading. The model describes an evolutionary equilibrium of low frequency traders (LFTs) who compete in portfolio management services by offering investment styles. The introduction of front-runners inflicts heavy losses on speculators, while leaving passive investors relatively unscathed. This encourages investment in the market portfolio and markedly reduces overall turnover. Speculative trading persists despite its lower profitability. By most measures, market quality is not affected to any significant extent by front-running HFTs.
\end{abstract}

Keywords: Front running; HFT; market quality.

JEL classification: D53; D47; C63, C73. 


\section{Introduction}

Financial markets are complex ecologies of interdependent market participants. Investors differ with respect to styles that focus on value, news, momentum, sectors, factors, etc. Moreover, markets rely on market makers to provide liquidity; price discovery by informed traders; speculators to correct temporary mispricings, as well as gamblers who are willing to lose enough money to pay for these services. In addition, there are predatory traders who make money by front-running or bluffing other traders. This diversity poses a challenge

to financial research because (1) regulations and innovations can affect different types of market participants in widely different ways, and (2) the interdependence between them renders partial analyses ineffective.

We believe that evolutionary approaches are well suited to study this type of interconnected systems, and in this paper, we use one such approach to ask how the advent of High Frequency Trading (HFT) can be expected to change the ecology of equity trading strategies. This is an interesting question because so far, despite many strong opinions raised in the public (cf. Lewis (2014)), very little is known about the impact of HFT on the whole ecology of the market.

The excellent recent surveys of the HFT literature by Menkveld (2016) and Biais \& Foucault (2014) stress several channels through which HFTs can profit from the relative slowness of other market participants.

HFTs engaged in market-making are able to trade less with informed traders since higher speed reduces the risk of having limit orders being picked off. As market makers lose to informed traders, being faster increases HFT market makers' profits as well as enables them to offer better prices and provide more liquidity to uniformed traders.

HFTs focussing on inter-market trading (at present using microwave communication infrastructure) reap the benefits from statistical arbitrage. Being the first to trade on information revealed in one venue (e.g., a stock market) at another venue (e.g., a derivative market), HFTs contribute to consistent pricing of financial assets across fragmented markets. For an 
illustration see Laughlin, Aguirre \& Grundfest (2014) who analyze latency in information transmission between E-Mini S \& P 500 futures traded in Chicago and SPY traded in New York.

HFTs can prey on large orders by front running. When front-running large market orders, an HFT takes liquidty and offers it at a worse price. This front-running strategy works by anticipating market orders (or marketable limit orders with price impact) from an investor, buying up liquidity using market orders and posting it at a less favorable price using limit orders. The original order is then executed at a worse price than anticipated by the investor. Hirschey (2013) finds that HFTs are able to anticipate order flow and can trade profitably (and predatorily) on this information This issue is of major concern to institutional investors, as for example Norges Bank Investment Management (2013), see also Tong (2015). In this paper, we aim to quantify the extent to which front-runners impact market quality and their impact on the market ecology.

Several aspects of the equity market plays into the hands of HFTs seeking to profit from front-running, see, e.g., Adrian (2016) and Biais \& Foucault (2014).

Exchanges sell co-location - space in the data center for a server (running automated trading software) close to the trading venue's matching engine. Co-location helps HFTs to submit orders fast but, more importantly, gives faster access to information on quotes and trades that originates from the matching engine. This creates an information asymmetry which benefits co-located HFTs.

If co-located HFTs were predominantly market-makers then, as argued above, co-location reduces the losses to informed traders which benefits uninformed market participants. These are typically small retail investors but, as observed by van Kervel \& Menkveld (2016), also large institutional investors because HFTs 'lean against the wind' up to a certain volume. Balancing the interests of LFT and HFT market participants, places market venues in a delicate position (see, e.g., Harris (2003, Part II)): Markets exist because utility-motivated traders want to exchange assets. Attracting and serving the needs of LFTs is therefore crucial 
to the viability of a venue. Since profit-motivated traders can facilitate this exchange, venues should attract HFTs that enhance liquidity. By some estimates the majority of HFT trades are market making, e.g., Hagströmer \& Nordén (2013), and Brogaard, Hagströmer, Nordén \& Riordan (2015) find that co-location improves liquidity. Tong (2015) claims that HFTs provide expensive liquidity.

Fragmentation of equity markets also benefits HFTs. Before 2009 US exchanges would 'flash' orders before forwarding these to the market if unfilled, thus making these orders potential prey for front-running, e.g. Securities and Exchange Commission (2009, p. 39/40). Since flashing is for about half a second, only HFTs could respond. An HFT could observe the flashed order and, rather than filling it at the NBBO, take liquidity at the venue with the best price and repost the volume at a worse price. The flashed order will end up being filled at a less favorable price than the one available at the time of flashing.

The decentralized structure of the US equity market allows to employ similar techniques even after the demise of 'flashing'. Since orders need to be filled at the NBBO (or at better prices), a large enough order will 'slosh' around the market, being filled - in the extreme case, lot by lot and revolve across different venues. Observing the arrival of an order at one venue, an HFT would then employ latency arbitrage by buying liquidity at other venues and selling it at a higher price. In response to latency arbitrage, smart order routers (automated order submission systems) break up large institutional orders into smaller 'child' orders, se e.g. Norges Bank Investment Management (2015).

Prior to 2005 some US market venues allowed quoting prices that give a price improvement of at least $1 / 100$ of a cent. Since the minimum tick size is 1 cent, this effectively allows traders to jump the price priority queue. Hence 'subpenny trading'. SEC Rule 612 banned placement of displayed subpenny quotes. The rule however does not preclude subpenny trading: Traders can for instance place hidden subpenny quotes, e.g. in dark pools, or offer ‘in-house' price improvement to incoming client orders (Dick 2010).

Other aspects of market venues can also benefit HTFs to the disadvantage of LFTs. 
Venues compete in fee structures, see, e.g., Harris (2015). Some markets offer taker-maker pricing, a fee structure that inverts the classical maker-taker pricing where limit orders get a rebate and market orders pay a fee. The idea behind the maker-taker pricing structure is to encourage liquidity provision. By paying a (small) additional amount of money when a limit order is hit, the liquidity provider (the 'maker') is compensated by more than the bid-ask spread when the provided liquidity is taken. The counterparty sending a market order (the 'taker') pays the rebate, plus possibly a small increment to the market venue.

Taker-maker pricing rewards submission of market orders. Although at first glance this might seem perverse, one has to look at the market from a market maker's perspective. While the bid-ask spread is the main profit generator, flow (volume) is needed as well. Taker-maker pricing encourages market orders, i.e., generates flow. But taker-maker pricing also opens opportunities for HFTs through subpenny trading (Buti, Consonni, Rindi, Wen \& Werner 2015). Taker-maker pricing also enables subpenny trading because the net quote, i.e., the effective quote after rebates/fees, differs from the displayed quote. One can then offer more aggressive limit orders by placing them at taker-maker rather than maker-taker venues (Harris 2015, p. 70/71).

We next describe a simple strategy to illustrate the profitability of predatory frontrunning. Consider the order book for a stock in Table 1.

Table 1: An order book

\begin{tabular}{cc|rr}
\hline Buyer depth & Bid & Ask & Seller depth \\
\hline 46 & 5.98 & 6.00 & 25 \\
80 & 5.96 & 6.01 & 115 \\
120 & 5.95 & 6.03 & 70 \\
\hline
\end{tabular}

Suppose a front-runner sees an incoming market buy order of size 100. Before it reaches the order book, the front-runner places a market buy order for 100. The order executes and moves the ask from 6.00 to 6.01. The front-runner next submits a limit sell order for 100 at 6.0099, which executes against the incoming (front run) market order. Total profit for the 
front runner (and cost for the incoming market order) is $6.0099 \times 100-6 \times 25-6.01 \times 75=0.24$. It is positive because the front-runner benefits from walking up the sell order book before selling to the incoming market order at the new and higher ask $!^{1}$

The limit sell order for 100 at 6.0099 does not obey the usual tick size. As explained above this order could be a hidden subpenny order or an in-house cross with an NBBO-improving price (6.0099 is better than the current ask of 6.01).

It is important to note that only market orders with market impact can be profitably front run. Therefore, since larger orders have more market impact, aggressive low frequency traders will pay more than passive ones if there are front runners in the market. Aggressive LFT traders include news traders and other short-term speculators. It is commonly assumed that the activity of such traders improve price discovery and other aspects of market quality. In this paper, we ask whether such traders will reduce their activity level in the presence of HFT front-runners, and if so, if market quality suffers as a result.

Our model describes financial markets from an evolutionary perspective to capture the complex ecology of many interdependent market participants. Building on Lensberg, SchenkHoppé \& Ladley (2015), we consider LFT investment funds and HFT front-runners interacting in a limit order market. The model presents a wide range of potentially important mechanisms whose equilibrium effects can be measured and compared in a coherent manner.

In the model traders' risk preferences and specific roles (news trader, value investor, liquidity provider, etc) are endogenous. There are no a priori assumptions on funds' equity trading strategies. Market equilibrium and rational behaviour of funds are the outcome of a competitive evolutionary process, as suggested by (Alchian 1950). In equilibrium, funds act 'as if' they were rational and the market is efficient. By pursuing this approach, we can encompass the intertwined changes in market quality and LFTs' behaviour in response to

\footnotetext{
${ }^{1}$ The front-runner could make more money by trading more aggressively: First, place a larger market buy order (140 instead of 100) in order to push up the ask to 6.03. Second, use a market sell order to dispose of 40 at the best bid of 5.98. Finally, use a limit sell order for 100 at 6.0299 to sell 100 to the incoming market order. This yields a net profit of 1.04, against 0.24 for the simple strategy. In his paper, we only consider simple front-running strategies.
} 
changes to the market environment due to front-running.

Within this framework the equilibrium effects of front-running HFTs can be quantified by comparing two scenarios: a market without resp. with front-running. The model contains a large number of fund managers who trade the stock and bonds issued by an aggregate firm. There is substantial endogenous heterogeneity among individual funds, and specialization on trading styles such as news trading, value trading and market making. We ask to what extent front-running impacts the portfolio holdings, order flow, liquidity, price discovery, short-term volatility and long-term price dynamics.

Evolutionary approaches using genetic algorithms to study trading in financial markets form a growing literature. Recent notable examples are Allen \& Karjalainen (1999), Arifovic \& Gençay (2000), Gradojevic \& Gençay (2013), Chiarella, He \& Wei (2015), Arifovic, Chiarella, He \& Wei (2016).

Our paper is closely related to Arifovic et al. (2016) who also analyze an evolutionary model of order-driven markets with HFT and LFT traders. Their main emphasis is on the role of information about fundamental values in the presence of different speeds of trading. HFTs can have both an informational and a speed advantage. In our paper, HFTs do not have any superior information about fundamental values. They only possess the ability to observe the order flow which is used for front-running. In this sense these two papers explore complementary issues.

\section{Model}

We give a short explanation of the model and refer the reader to Lensberg et al. (2015) for further details.

Earnings per share of the aggregate firm are determined by a geometric Ornstein-Uhlenbeck stochastic process with a time-varying mean $\mu^{s_{t}}$, where $s_{t}$ is the (unobservable) state of the economy at time $t$. The economy is either in expansion $\left(s_{t}=1\right)$ or contraction $\left(s_{t}=0\right)$. 
Bonds are risk-free consols, and dividends equal total earnings minus total interest payments.

Shares are traded against bonds in a continuous market with a limit order book. Fund managers arrive at the market at random times and can submit marketable limit orders. An order crossing the spread is a market order and is immediately executed. Partial execution is possible with the unfilled quantity of the order being added to the book. An order that is behind the market, i.e., does not cross the spread, is added to the book where it stays until it is executed or a new order is submitted by the trader. The usual price-time priority in order execution applies.

Margin trading is allowed subject to a $50 \%$ initial and 33\% maintenance margin requirement. This means that funds can sell short as well as leverage long but only to the extent that they meet these margin requirements. Margin violations lead to margin calls and the automatic submission of market orders to restore the margin requirement. Bankrupt funds are removed from the market and their holdings are distributed among all non-bankrupt funds in proportion to their managed wealth.

Each fund has a quantitative trading strategy, represented as a computer program that maps input data to limit orders. Input data consist of market data (bid, ask and quantities at these prices, change of mid price in the last 24 hours), fundamental information (riskneutral price (RNP) of the stock), news (change in RNP in the last 24 hours), current portfolio holdings, and the state of the margin account. Limit orders consist of a price and a quantity.

The model is calibrated to the current U.S. market by either drawing on empirical observations or choose parameter values that give results consistent with historical averages and stylized facts of the business cycle, aggregate earnings and earnings surprises (details are provided in Lensberg et al. (2015)).

The market is populated with 20,000 funds. This number is motivated by U.S. institutional investment industry research that puts the number of mutual funds at around 8,000 (Investment Companies Institute (ICI)'s 2017 Investment Company Fact Book) and that of 
traditional hedge funds at 7,500-8,000 (eVestment).

Funds compete for survival in a market for portfolio management services, where high performing funds attract clients from low performing ones. The evolution of strategies in the market is modeled in terms of a genetic programming algorithm with tournament selection. At the end of every trading day (250 per year), there are four tournaments. In each tournament, eight funds are randomly selected and ranked by wealth under management. The computer programs of the worst two are replaced by copies of the computer programs of the two best ones. Then, with certain probabilities, the two copied programs are subject to random crossover and mutation. This yields a $10 \%$ p.a. exit/entry rate which is in line with the attrition rate of US equity fund managers (Busse, Goyal \& Wahal 2010) and hedge funds (Preqin, Hedge Funds in 2016). Hedge fund launch sizes are estimated using data from AIMA/GPP (Emerging Managers Survey 2017) and eVestment (Alternatives Research, Impact of Age and Size on Hedge Fund Performance, July 2015). Computing the mean assets under management of new funds relative to the industry average, we obtain estimates of $9 \%$ and $32 \%$ respectively. Based on these observations we endow new funds with $20 \%$ of the average portfolio.

While individual funds can only increase their managed wealth through superior portfolio returns, the evolutionary process selects for just those strategies which yield superior performance. This leads to an increase in the number of funds that follow similar strategies. In equilibrium, surviving strategies tend to cluster around a small number of distinct investment styles. The ecology of the market is given by these styles and the total assets under management of each style.

Data set. Two scenarios are considered: A benchmark scenario (BAS) with only low frequency traders, and a second scenario (HFT) which also includes a high frequency trader. The behaviour of the HFT is exogenous to the model: It uses the simple front-running strategy discussed in connection with Table 1 against all incoming market orders from LFTs. This assumption on front-running is more convenient (and simpler) than using more sophisticated 
(and more profitable) predatory strategies but having HFTs anticipating only part of the order flow (and thus miss out on a proportion of profitable trades). To implement the simple front-running strategy, an HFT only requires knowledge about the size of the arriving order, the state of the book and the ability to place an order in front of the incoming one; features that are inherently provided by co-locating and subscribing to fast inter-market connections.

Comparing the market dynamics and LFT behaviour between these two scenarios, we can assess the impact of front-running HFTs on market quality, informational efficiency and investor behaviour. For each scenario, we do 200 independent runs with the model. Each pair of runs uses identical seeds for the random number generator. This means, in particular, that sample paths for the earnings process are identical across scenarios for the same run. In this manner, we obtain two data sets, each consisting of 200 independent observations which allow for pairwise comparisons between scenarios at any time scale.

The BAS scenario is identical to the base case of Lensberg et al. (2015). For each one of 200 runs, the model is solved by running it for 15 million trading days. At that point, the pricing process passes some standard tests of rationality and dynamic stability, i.e., the model is judged to have converged to a 'steady state.' The HFT scenario is identical to the BAS scenario during the first 10 million trading days. At that point, we introduce the high frequency trader who continues to follow its front-running strategy during the remaining 5 million trading days.

After 15 million trading days, we run the models for an additional 10,000 trading days to collect data. The data include measures of trading behaviour, market quality, and frontrunning costs. The latter are costs to LFTs of doing business with front-runners. We distinguish between the impact and equilibrium effects on front-running costs. The impact effect would be the cost paid by LFTs if they did not change their behaviour in response to the introduction of the HFT, and the equilibrium effect is the cost they pay after having adapted their behaviour to the new situation. The impact and equilibrium effects are measured with data from the BAS and HFT scenarios, respectively. 


\section{Results}

Results on the impact and equilibrium effects of HFT are organized in two parts. The first part analyzes aspects of market quality: Price discovery; Short-term price fluctuations; Long swings and Liquidity (Table 2). The second part is concerned with investor behaviour (Table 4). We classify the traders by their portfolio position (Short, Only bonds, Mostly bonds, Market portfolio, Mostly stock, Only stock, and Leveraged long) and analyze the effect of the BAS and the HFT scenarios on these types: relative frequency, wealth under management, trading activity, limit vs market order usage, and loss to front-runners.

\subsection{Market quality}

Price efficiency. Speculators contribute to price discovery by trading mispriced assets. They make money by trading aggressively on short-term informational advantages. Speculators are therefore particularly vulnerable to front-running. This leads to the hypothesis that front-running HFTs will reduce price efficiency. To test the hypothesis, we regress daily log stock returns on daily log innovations to RNP (the risk-neutral price of the stock), and use the corresponding $R^{2}$ 's as our measure of price discovery. We also test for asymmetric price responses to good and bad news by computing upside and downside $R^{2}$ 's for days with an increasing (decreasing) RNP.

Panel (1) of Table 2 contains the results. We find no significant differences between the two scenarios. Mean stock prices are the same, price discovery $\left(R^{2}\right)$ and price response to good/bad news ( $R^{2}$ down-up) are unchanged. There is no evidence that front-runners harm price efficiency.

Short- and long-term price fluctuations. We next ask whether front-runners destabilize the market by increasing price fluctuations. Front-runners' trading could increase excess volatility in the short run by triggering cascades of buying or selling. They could also make long-term swings in the market more pronounced if their presence leads to a flight to safety 
Table 2: Market quality indicators. (1) Price discovery. For each scenario and run, we compute the $R^{2}$ obtained by regressing daily log returns on daily log innovations in the RNP of the stock. Upside and downside $R^{2}$ are calculated in the same way, except for restricting the data to days with a nondecreasing and decreasing RNP, respectively. Downside-minus-upside $R^{2}$ is the difference between the downside and the upside $R^{2}$. (2) Short-term price fluctuations. Annualized volatility, skewness and excess kurtosis are computed by run from daily log-returns. (3) Long swings. For each scenario, Peak-to-trough is the mean percentage decline in the stock price from the peak in an expansion to the trough in the subsequent recession. An expansion (recession) is defined as an interval of trading days $T=\left\{t_{1}, \ldots, t_{k}\right\}$ such that the state variable $s_{t}$ is $1(0)$ on all days in $T$ and 0 (1) on days $t_{1}-1$ and $t_{k}+1$. There are 687 of these events across the 200 independent runs of the model. High (Low) is the mean across 200 runs of the maximum (minimum) closing stock price across all 10,000 trading days of that run. Range is the difference between High and Low. (4) Liquidity. The bid-ask spread is the difference between the closing ask and bid. Market impact is the difference between the current bid (ask) and the average execution price of a market sell (buy) order. Round-trip cost is the bid-ask spread plus two times the market impact. Turnover per day is trade volume divided by the number of shares outstanding. Days between trades is the average number of days between two consecutive trades by the same investor. Order size on a given day is trade volume divided by the number of trades. Except for Panel (3) Long swings, the data sets consist of 200 run means of daily observations of each variable. P-values in parentheses are computed from paired t-tests of differences in means between the HFT scenario and the base case.

\begin{tabular}{lrrr}
\hline (1) Price discovery & BAS & HFT & P-value \\
\hline Stock price & 15.37 & 15.43 & $(0.486)$ \\
$R^{2}(\mathrm{dp}=a+b \cdot \mathrm{dRNP})$ & 0.874 & 0.874 & $(0.973)$ \\
$R^{2}$ down-up & 0.037 & 0.030 & $(0.270)$ \\
\hline (2) Short-term price fluctuations & & & \\
\hline Volatility (annualized) & 17.36 & 17.04 & $(0.369)$ \\
Skewness & 0.08 & 0.22 & $(0.434)$ \\
Excess kurtosis & 18.34 & 35.49 & $(0.149)$ \\
\hline (3) Long swings & & & \\
\hline Peak-to-trough (\%) & 43.14 & 42.65 & $(0.209)$ \\
High & 21.49 & 21.32 & $(0.628)$ \\
Low & 8.16 & 8.23 & $(0.514)$ \\
Range & 13.33 & 13.09 & $(0.551)$ \\
\hline (4) Liquidity & & & \\
Bid-ask spread (bp) & 10.18 & 10.19 & $(0.948)$ \\
Market impact (bp) & 1.07 & 1.15 & $(0.087)$ \\
Roundtrip cost (bp, ex. front-running cost) & 12.32 & 12.50 & $(0.484)$ \\
Turnover per day (\% of outstanding shares) & 2.46 & 1.90 & $(0.000)$ \\
Days between trades & 5.23 & 5.48 & $(0.000)$ \\
Order size (number of shares) & 6,067 & 4,882 & $(0.000)$ \\
Order book depth (market impact of 50K shares) & 3.11 & 3.70 & $(0.000)$ \\
\hline
\end{tabular}

by LFTs in bad times.

Panel (2) of Table 2 contains results on short-term price fluctuations. We report volatility, 
skewness and kurtosis for daily returns. There are no significant differences between the BAS and the HFT scenario.

Long swings in prices across business cycles are measured as the mean percentage decline in the stock price from a peak in an expansion to the trough in the subsequent recession. This is the 'Peak-to-trough' variable in Panel (3) of Table2, The variables 'High' and 'Low' are the means of maximal and minimal stock prices across 200 40-year periods, and 'Range' is the difference between 'High' and 'Low.' We find no significant differences in any of these results.

Liquidity. We measure liquidity in several dimensions: quoted bid-ask spread, price impact (slippage) of market orders, roundtrip cost, order book depth, daily LFT turnover, and average LFT order size. For the HFT scenario, all measures include the equilibrium effects on the order book by HFTs, but their immediate effects are excluded. In particular, the slippage of a particular market order is computed under the assumption that the order will not be subject to front-running. The immediate impact of front-running HFTs on transaction costs are considered separately in the next subsection.

Panel (4) of Table 2 collects the results on liquidity. It shows that front-running by HFTs has a significant negative effect on trading activity and market depth: Trade volume and order book depth are both reduced, and LFTs trade less frequently in smaller order size. However, the table also shows that the market digests these negative volume effects without affecting equilibrium transaction costs, as measured by the bid-ask spread and market impact.

Summing up, we find that front-running reduces trading activity without affecting other aspects of market quality. The latter may seem to be at odds with the empirical literature, which reports significant effects of HFT activity on price discovery, short-term volatility and transaction costs (Menkveld 2016). Two differences between our approach and the existing literature could account for this apparent anomaly: First, we isolate the effect of front-running from other aspects of HFT behaviour, such as market marking, arbitrage, and 
momentum strategies. Front-running in our model affects about $20 \%$ of the trading volume, which is only a part of the total activity of HFT trading reported in the empirical literature (Brogaard (2010)). Second, our data are obtained from controlled experiments where the effects of HFTs are measured across a large number of very long time periods.

We provide an example to illustrate these points. Many authors have found evidence that HFT activity increases intraday volatility. To obtain a standard test of this hypothesis we use data from the HFT scenario only. We represent HFT activity by HFT trade volume and measure intraday volatility as the root mean of volume-weighted relative variances of daily transaction prices. Table 3 contains the results, and Model (1) seems to indicate that HFT activity increases intraday volatility.

But this effect is driven by exogenous differences between business cycles across runs, with corresponding differences in market distress, volatility, and aggressiveness of low frequency traders. Since the front-running HFTs prey on aggressive LFTs, we observe a spurious positive relationship between volatility and HFT activity. Table 3 supports these claims by showing that nothing significant is left to be explained by HFT activity if one controls for Market distress and LFT aggressiveness. This agrees with the results on daily volatility in Table 2, where the confounding factor has been eliminated by comparing data across 200 identical pairs of business cycle realizations. We can conclude that if HFTs increase short-term volatility, it must be due to other HFT activities than front-running.

Table 3: Effect of HFT trade volume on Intraday volatility, defined as the root mean across all trading days of volume-weighted relative variances of daily transaction prices. Market distress is represented by the state variable $\left(1-s_{t}\right)$, which is 1 if the economy is in a downturn. LFT aggressiveness is the fraction of LFTs who hold short or leveraged long positions (margin traders). Such traders are conspicuous for trading frequently in large size, cf. Section 3.2. OLS on standardized variables with robust standard errors. P-values in parenthesis.

\begin{tabular}{lccc}
\hline & $(1)$ & $(2)$ & $(3)$ \\
\hline HFT trade volume & $0.322(0.015)$ & $0.222(0.077)$ & $0.193(0.129)$ \\
Market distress & & $0.390(0.000)$ & $0.365(0.000)$ \\
LFT aggressiveness & & & $0.220(0.000)$ \\
\hline Observations & 200 & 200 & 200 \\
Adjusted R & & 0.238 & 0.282 \\
\hline
\end{tabular}




\subsection{Investor behaviour}

We now turn to the effect of HFT on the behaviour of investors. In particular we want to understand why and how trading activity is reduced, as observed in Section 3.1.

Traders are classified by portfolio position which are categorized into 7 types: Short, Only bonds, Mostly bonds, Market portfolio, Mostly stock, Only stock, and Leveraged long. For instance, Short comprises investors who sold the stock short and have a negative position in the stock. Leveraged long are all investors who borrow to buy the stock. Lensberg et al. (2015) found marked differences in the behaviour across these types. We therefore ask here whether and how they react differently to HFT.

Table 4 contains results on the effect of HFTs on the investor population, the behaviour of different types and their trading costs. The table contains four panels of variables: (1) Three frequency distributions of trader types; (2) Order usage for each trader type (limit, market and no order), (3) Two measures of trading activity, and (4) Two measures of front-running (FR) costs.

The top panel (1) of Table 4 shows that close to half of total wealth under management is held by funds who invest in the market portfolio. Only about $15 \%$ of the wealth is held by traders who are long in one asset only (Short, Only bonds, Only stock and Leveraged long), but these traders represent almost half the population and they submit $50 \%$ of all orders.

These findings reveal a market populated by investors who range from small active funds with extreme positions (Speculators) to large passive funds who hold the market portfolio (Index funds). The effect of introducing front-running HFTs is a small, but significant increase in the number of index funds (as well as a matching increase in the proportion of submitted orders), and a corresponding reduction of traders with speculative positions.

Panel (2) of Table 4 contains information about order usage. Overall, the traders place 2-3 times more limit than market orders, and index funds are least likely to use market orders. Speculative traders respond to front-running by a slight, but significant reduction in their use of market orders. Index funds do not change the composition of their order flow. 
Table 4: Summary statistics by traders' portfolio positions. Let $(\alpha, \beta):=(S / \mathcal{S}, B / \mathcal{B})$ for a portfolio with $S$ stocks and $B$ bonds, where $(\mathcal{S}, \mathcal{B})$ is the current number of stocks and bonds outstanding. If $\alpha+\beta>0$, we define $\lambda=\alpha /(\alpha+\beta)$ and classify the portfolio as Short if $\lambda<-0.05$; Only bonds if $-0.05 \leq \lambda<0.05$; Mostly bonds if $0.05 \leq \lambda<0.35$; Market portfolio if $0.35 \leq \lambda<0.65$; Mostly stock if $0.65 \leq \lambda<0.95$; Only stock if $0.95 \leq \lambda<1.05$; and Leveraged long if $\lambda \geq 1.05$. If $\alpha+\beta \leq 0$, the portfolio is classified as Short if $\alpha<0$, and as Leveraged long if $\beta<0$. Investors with portfolios such that $\alpha \leq 0$ and $\beta \leq 0$ are bankrupt and excluded from the classification. For each scenario, run, and variable, we compute a histogram on the bins of this classification. The number of observations is 200 in each scenario. P-values of t-tests of differences in means between the two scenarios are represented as $\mathbf{p}<\mathbf{0 . 0 1} ; 0.01 \leq \mathrm{p}<0.05$; and $\mathrm{p} \geq 0.05$.

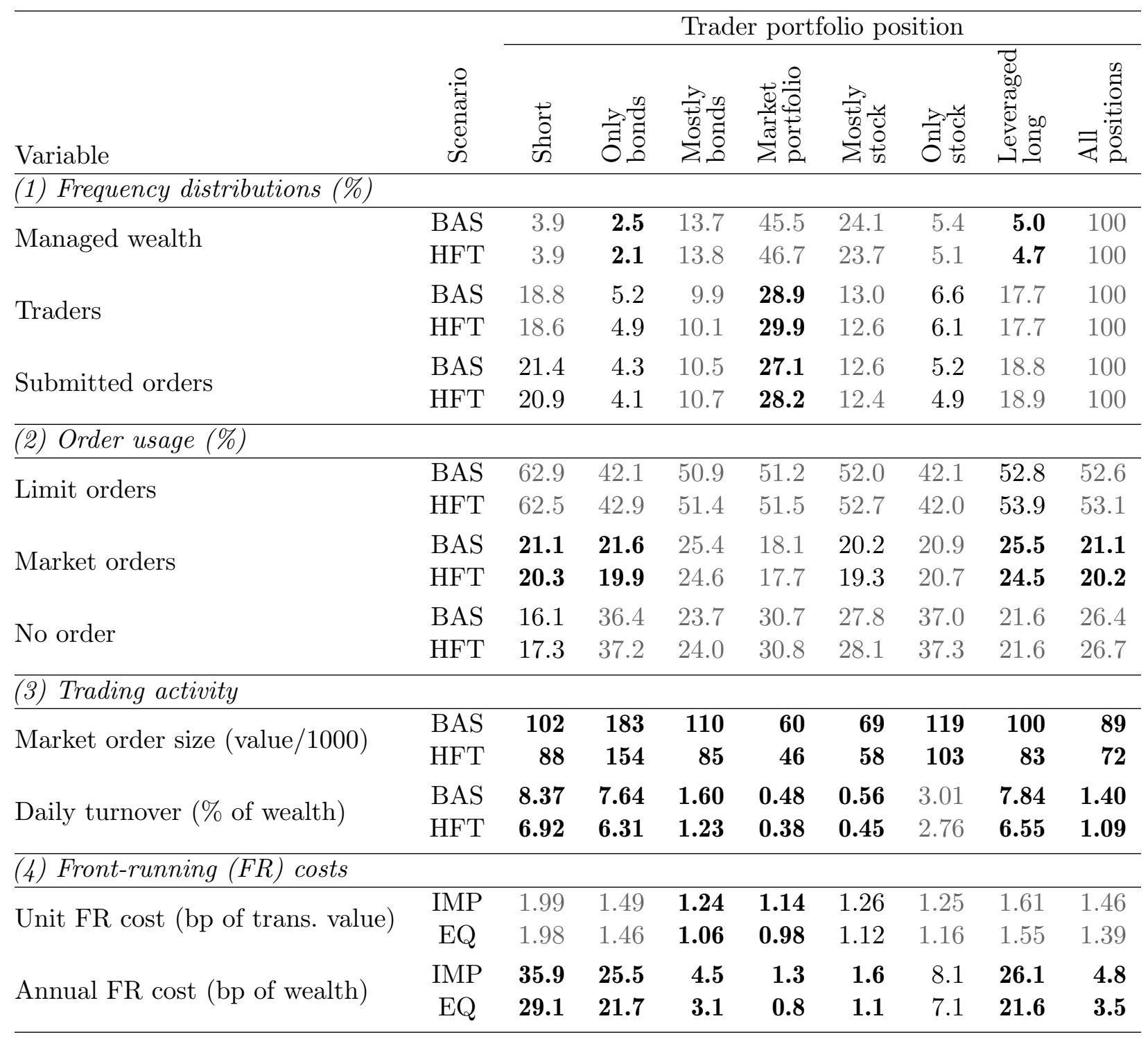

Panel (3) depicts market order size and daily turnover across trader types. Speculators submit orders almost twice as large as those of index funds, and their turnover (measured 
as percentage of wealth under management) is more than 15 times larger. Front-running by HFTs causes most trader types to reduce the size of their market orders by $15-20 \%$, which leads to a similar reduction in their turnover.

Panel (4) shows the costs incurred by trading with front-runners. IMP and EQ denote the impact and equilibrium costs, computed from scenarios BAS and HFT respectively. The impact cost is the cost to LFTs if they did not change their behaviour in response to front-running. The equilibrium cost is the actual cost incurred.

Annual impact costs relative to managed wealth range from 1.3 basis points for index funds to $35.9 \mathrm{bp}$ for traders with short positions. Equilibrium costs are lower than impact costs for all trader types, but with substantial variations in relative difference. By changing their trading behaviour, speculative traders save $20 \%$ on their impact cost against $40 \%$ for index funds. This reduction in cost is a combination of many factors: trade frequency, order aggressiveness, order size relative to liquidity and order timing. Measuring the difference between impact and equilibrium cost relative to transaction value (unit FR costs), we find that index funds save $14 \%$ over their impact costs, while for speculative traders there is no significant difference.

Our results show that speculators respond less strongly to front-running than index funds. The latter markedly reduce their losses to front-runners by changing trading behaviour. Speculators, in contrast, are less successful at reducing losses due to front-running.

Since many speculators make money by trading large size on short-lived information advantages (see Lensberg et al. (2015), Table 9 and discussion the on page 113), they have limited opportunities to search or, in the present model, wait, for good liquidity. Index funds do not face this tradeoff because they can trade less with greater patience. In the presence of front-runners this makes a substantial difference. Although speculators lose up to 29bp per annum to front-runners, their number and wealth under management remains nearly unchanged. This is consistent with our finding that front-runners do not reduce the overall market quality. 
The absence of a major change in the composition of the investor population shows that the BAS scenario is quite robust to small increases in unit transaction costs. This result can be interpreted from an evolutionary perspective. Small funds must deliver superior performance in order to attract clients, but in an efficient market there is no strategy that can be expected to achieve that goal. In particular, hiding in the crowd of index funds is not a viable alternative. Superior performance can only be achieved by chance, and this requires some amount of gambling. Our results on unit FR costs in panel (4) of Table 4 show that small funds are willing to pay a net fee of one basis point for a chance to beat the market portfolio.

\section{Conclusion}

Front-running by HFTs extracts rents from investors who need to trade large size quickly. In our model, these investors are speculators who seek to gain from news events and short-term mispricing. Index funds who tend to hold large market portfolios are much less affected. They become more patient and trade more carefully in the presence of HFTs.

Overall, turnover is lower in the presence of front-running HFTs, and there is a small but significant tendency to invest more in the market portfolio. By most measures, market quality is not affected to any significant extent by front-running HFTs. Speculative trading persists despite its lower profitability because market efficiency forces small funds to gamble in order to survive.

\section{References}

Adrian, J. (2016). Informational Inequality: How High Frequency Traders Use Premier Access to Information to Prey on Institutional Investors, Duke Law $\mathbb{3}$ Technology Review 14: 256-279. 
Alchian, A. A. (1950). Uncertainty, Evolution, and Economic Theory, Journal of Political Economy 58: 211-221.

Allen, F. \& Karjalainen, R. (1999). Using Genetic Algorithms to Find Technical Trading Rules, Journal of Financial Economics 51: 245-271.

Arifovic, J., Chiarella, C., He, X. \& Wei, L. (2016). High Frequency Trading and Learning. Working Paper, available at SSRN: https://ssrn.com/abstract=2771153.

Arifovic, J. \& Gençay, R. (2000). Statistical Properties of Genetic Learning in a Model of Exchange Rate, Journal of Economic Dynamics $\&$ Control 24: 981-1005.

Biais, B. \& Foucault, T. (2014). HFT and Market Quality, Bankers, Markets \& Investors 128: $5-19$.

Brogaard, J. (2010). High Frequency Trading and Its Impact on Market Quality. Working Paper.

Brogaard, J., Hagströmer, B., Nordén, L. \& Riordan, R. (2015). Trading Fast and Slow: Colocation and Liquidity, Review of Financial Studies 28: 3407-3443.

Busse, J. A., Goyal, A. \& Wahal, S. (2010). Performance and Persistence in Institutional Investment Management, Journal of Finance 65: 765-790.

Buti, S., Consonni, F., Rindi, B., Wen, Y. \& Werner, I. M. (2015). Sub-Penny and QueueJumping.

Chiarella, C., He, X. \& Wei, L. (2015). Learning, information processing and order submission in limit order markets, Journal of Economic Dynamics and Control 61: 245-268.

Dick, D. (2010). The Hidden Cost of "Sub-Pennying", CFA Magazine Jan-Feb: 8-9.

Gradojevic, N. \& Gençay, R. (2013). Fuzzy Logic, Trading Uncertainty and Technical Trading, Journal of Banking $\mathscr{G}$ Finance 37: 578-586. 
Hagströmer, B. \& Nordén, L. (2013). The Diversity of High-frequency Traders, Journal of Financial Markets 16: 741-770.

Harris, L. E. (2003). Trading and Exchanges: Market Microstructure for Practitioners, Oxford University Press.

Harris, L. E. (2015). Trading and Electronic Markets: What Investment Professionals Need to Know, CFA Institute.

Hirschey, N. (2013). Do High-Frequency Traders Anticipate Buying and Selling Pressure? Working Paper.

Laughlin, G., Aguirre, A. \& Grundfest, J. (2014). Information Transmission between Financial Markets in Chicago and New York, Financial Review 49: 283-312.

Lensberg, T., Schenk-Hoppé, K. R. \& Ladley, D. (2015). Costs and Benefits of Financial Regulation: Short-selling Bans and Transaction Taxes, Journal of Banking \& Finance 51: 103-118.

Lewis, M. (2014). Flash Boys: A Wall Street Revolt, Norton and Norton Publishers.

Menkveld, A. J. (2016). The economics of high-frequency trading: Taking stock, Annual Review of Financial Economics 8: 1-24.

Norges Bank Investment Management (2013). High Frequency Trading An Asset Managers Perspective. NBIM Discussion NOTE \#1 - 13.

Norges Bank Investment Management (2015). Sourcing Liquidity in Fragmented Markets. NBIM Discussion NOTE \#1 - 15 .

Securities and Exchange Commission (2009). Elimination of Flash Order Exception from Rule 602 of Regulation NMS. RIN 3235-AK40. 
Tong, L. (2015). A Blessing or a Curse? The Impact of High Frequency Trading on Institutional Investors. Working paper.

van Kervel, V. \& Menkveld, A. J. (2016). High-Frequency Trading around Large Institutional Orders. Working paper. 